\title{
TURBULENCE IN AN ALMOND ORCHARD: VERTICAL VARIATIONS IN TURBULENT STATISTICS
}

\author{
DENNIS D. BALDOCCHI and BOYDA. HUTCHISON
}

Atmospheric Turbulence and Diffusion Division/NOAA/ARL P.O. Box 2456, Oak Ridge, TN 37831, U.S.A.

(Received in final form 30 March, 1987)

\begin{abstract}
Three-dimensional wind velocity components were measured above and within a uniform almond orchard. Turbulent statistics associated with the turbulent flow inside the canopy are examined in detail. Turbulence in an almond orchard is characterized by relatively high turbulent intensities and large skewness and kurtosis values. These results indicate that the frequency distribution of wind velocity components is non-Gaussian. Conditional sampling of the turbulent measurements show that large, infrequent sweeps provide the predominant mechanism for tangential momentum stress in the canopy crown. Deep inside the canopy, a secondary wind maximum and small, but positive, tangential momentum stresses are observed.
\end{abstract}

\section{Introduction}

Turbulent flow is defined as the motion of a fluid having local velocities and pressures that fluctuate randomly. Inside a plant canopy, the complexity of turbulent flow is enhanced since turbulence is affected by the interactions between wind and the vegetation and the soil surface (see Finnigan and Raupach, 1987; Raupach and Thom, 1981). Processes governing turbulent flow in plant canopies can be described qualitatively as follows: (a) the aerodynamic drag of plant-parts extracts momentum from the mean flow; (b) plant-parts break down large-scale eddies into smaller eddies; (c) they convert kinetic energy of the mean flow into turbulent kinetic energy in wakes which form behind obstructing elements (Wilson and Shaw, 1977; Raupach and Thom, 1981); and (d) in aeroelastic canopies, mean kinetic energy is utilized to create waving of the foliage (see Finnigan, 1985).

The conservation equations for mass, energy, and momentum are generally used as a framework to study turbulence in a plant canopy. Under steady-state conditions, these equations contain terms for advection, the source or sink strength of the entity of interest and the divergence of the turbulent transfer of the entity (e.g., Raupach and Shaw, 1982; Finnigan, 1985). Early theoretical representations of turbulent transfer in plant canopies relied on first-order closure or ' $K$-theory' models, where a flux is defined as the product of the vertical gradient of the entity and the eddy diffusivity of that entity $(K)$ (e.g., Brown and Covey, 1966). Current turbulence theory demonstrates that ' $K$-theory' is applicable only if turbulent length scales are much smaller than the distance associated with changes in the vertical concentration gradient of the entity (Corrsin, 1974; Bache, 1986).

Field and wind tunnel measurements indicate that turbulent transfer in plant canopies is dominated by large intermittant eddies, whose wavelengths exceed the characteristic length scales of the canopy and its elements (Allen, 1968; Finnigan, 1979a; Raupach et al., 1966) and the mean vertical concentration gradient (Denmead and Bradley, 1985). 
Thus, a criterion needed to apply ' $K$-theory' is often violated. Furthermore, countergradient flow commonly occurs in plant canopies (Finnigan, 1979a; Denmead and Bradley, 1985). ' $K$-theory' models cannot predict counter-gradient flow since the concept of an eddy diffusivity does not admit negative values.

Higher order closure and Lagrangian models have been advocated to describe turbulent transfer in plant canopies since such models are formulated according to the governing conservation equations and because such models simulate profiles and fluxes of entities realistically (e.g., Shaw, 1976; Wilson and Shaw, 1977; Finnigan, 1985; Finnigan and Raupach, 1986; Meyers and Paw U, 1986; Raupach, 1987). The general utility of higher-order closure models is somewhat limited since such models rely on assumptions regarding the functional relationships of the higher order moments to close the set of conservation equations. Utility of Lagrangian models is limited by the need to specify length and time scales and the wind field (see Raupach, 1987). Most of the parameterizations for the higher-order moments and Lagrangian length- and time-scales and most of the tests of higher order closure and Lagrangian models are based on few available data sets from agricultural crops (wheat, Finnigan, 1979a, b; corn, Shaw et al. , 1974, 1983; and Wilson et al., 1982). Measurements of turbulent statistics in forests and orchards are, thus, needed to develop further and test within-canopy turbulent transfer models. Measurement of turbulent statistics in forests and orchards are also needed to improve our understanding of smoke, pollen and pesticide dispersal.

Recently, we participated in a cooperative wind experiment (project WIND) conducted in an almond orchard by the U.S. Forest Service and the U.S. Army Atmospheric Science Laboratory. This experiment provided an opportunity to study within-canopy wind flow in an 'ideal forest' on level terrain. Our goal was to examine the spatial variability of turbulence in the canopy. We first measured turbulent flow at two levels in the almond orchard canopy and, later, measured the spatial variation of turbulence near the orchard floor. In this paper, we discuss the vertical variations in turbulent statistics derived from sonic anemometer measurements. Turbulence spectra and the horizontal variability in within-canopy turbulence are discussed elsewhere (Baldocchi and Hutchison, 1987).

\section{Materials and Methods}

\subsection{SitE AND CANOPY CHARACTERISTICS}

Three-dimensional wind velocities were measured in a fully-leaved almond (Prunus amygdalus) orchard (Figure 1), located north of Chico, CA (lat. $39^{\circ} \mathrm{N}$; long. $121^{\circ} \mathrm{W}$ ). The experiment was conducted between late April and early May, 1986. The trees were about $8 \mathrm{~m}$ tall and were planted in a square pattern on approximately $8 \mathrm{~m}$ centers. Branching began at approximately $1.3 \mathrm{~m}$ above the ground and the boughs of the tree canopy mostly touched near the center of the rows. The leaf area index of the canopy was about 1.3. The vertical profile of leaf area is presented in Baldocchi and Hutchison (1987). The mean canopy drag coefficient $\left(u_{*} / u\right.$, where $u_{*}$ is friction velocity and $u$ is 


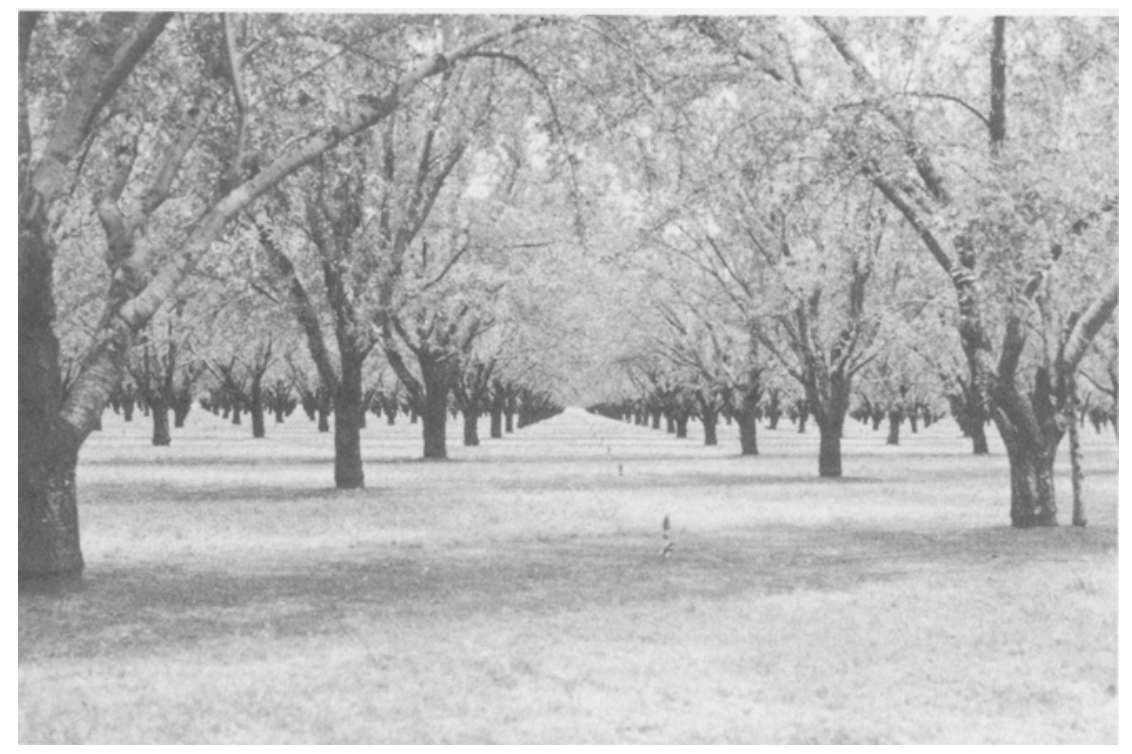

Fig. 1. Photograph of the almond orchard.

wind speed at 1.26 times canopy height) was $0.15 \pm 0.02$ for near neutral conditions. The size of the orchard was about $32 \mathrm{ha}$. It was surrounded by other orchards on the west, south and east sides. The fetch during these measurements was about $300 \mathrm{~m}$.

\subsection{INSTRUMENTATION}

Three-dimensional wind velocity components were measured inside the canopy with sonic anemometers (Applied Technology Inc., Boulder, CO, Model BH-478B/3). The anemometers were supported on a tower located at the midpoint between tree rows and columns. The anemometers were located at 0.51 canopy height $(h)$ and at $0.14 h$. The upper instrument was in the middle of the canopy crown. The lower instrument was in the subcanopy trunkspace. The horizontal axes were leveled to within one degree of horizontal. The azimuth angle of the anemometer booms was oriented so the wind generally flowed into the sensor head, to minimize transducer shadowing errors (Wyngaard and Zhang, 1985). The anemometers were extended about $3 \mathrm{~m}$ from the center of the support tower, resulting in the sensor head being about $3.3 \mathrm{~m}$ in the lee of an upwind tree. The sonic anemometer signals were sampled and digitized at a rate of about $5 \mathrm{~Hz}$ with a computer-controlled data acquisition system. Instantaneous data were transcribed to a magnetic disk during selected periods for post-processing. Realtime means, variances, covariances and third-order moments were computed for halfhour intervals to allow in-field analysis and quality assurance inspection. Power spectra of the velocity components show that the signals were not contaminated by noise (Baldocchi and Hutchison, 1987).

Three-dimensional wind speed components were measured above the canopy (1.26h) with a Gill uvw propeller anemometer (R. M. Young Co., Traverse City, MI). Net 
radiation was measured above the canopy with a net radiometer (Swissteco, LTD, Melbourne, Australia, Type S-1). Air temperature was measured at $1 \mathrm{~m}$ with a platinum resistance thermometer. These instruments were sampled at a rate of $1.2 \mathrm{~Hz}$ with a micrologger data acquisition system (Campbell Scientific Instrument Co., Logan, UT, model CR-21X). Data were stored as $\frac{1}{2}$-hr averages on magnetic tape. Above-canopy tangential momentum stress was computed in real-time as the mean covariance between fluctuations in vertical and horizontal wind velocities.

\subsection{DATA PROCESSING}

A one-dimensional coordinate rotation was applied to the data, making $u$ the streamwise velocity and $v$ the lateral component. Instantaneous wind velocity components were computed as:

$$
\begin{aligned}
& u=u_{i} \cos \theta+v_{i} \sin \theta, \\
& v=v_{i} \cos \theta+u_{i} \sin \theta,
\end{aligned}
$$

where $\cos \theta=\bar{u}_{i} /\left(\bar{u}_{i}^{2}+\bar{v}_{i}^{2}\right)^{0.5}, \sin \theta=\bar{v}_{i} /\left(\bar{u}_{i}^{2}+\bar{v}_{i}^{2}\right)^{0.5}$, the subscript $i$ denotes the initial value and the overbar represents time-averaging. The vertical velocity component, $w$, was not rotated to zero since non-zero values inside the canopy are possible, unlike above the canopy where they may be an artifact of streamline deformation due to sloping terrain, tower interference or sensor-head flow distortion.

The data presented below were obtained on D122 (May 2), 1986 between 0830 and $1400 \mathrm{hr}$. A $\frac{1}{2}$-hr averaging period was used. Mean above-canopy atmospheric conditions are presented in Table I. We were unable to measure heat flux and stability above the canopy due to sensor and data-logging limitations. This period, however, was windy and cloudy, as indicated by the low values of net radiation. Atmospheric stability, therefore, should have been near-neutral throughout most of the measurement period.

\section{TABLE I}

Above-canopy ambient conditions on D122, 1986 over an almond orchard

\begin{tabular}{llllll}
\hline $\begin{array}{l}\text { Time } \\
(\mathrm{hr})\end{array}$ & $\begin{array}{l}\text { Wind speed } \\
\text { at } 1.26 h \\
\left(\mathrm{~m} \mathrm{~s}^{-1}\right)\end{array}$ & $\begin{array}{l}u_{*} \\
\left(\mathrm{~m} \mathrm{~s}^{-1}\right)\end{array}$ & Wind direction & $\begin{array}{l}\text { Net } \\
\text { radiation } \\
\left(\mathrm{W} \mathrm{m}^{-2}\right)\end{array}$ & $\begin{array}{l}\text { Air } \\
\text { temperature } \\
(\mathrm{C})\end{array}$ \\
\hline 9.0 & 3.78 & 0.56 & 139 & 154 & 15.6 \\
9.5 & 4.04 & 0.60 & 136 & 155 & 15.8 \\
10.0 & 4.02 & 0.60 & 138 & 236 & 16.6 \\
10.5 & 4.10 & 0.61 & 144 & 297 & 17.8 \\
11.0 & 4.06 & 0.60 & 144 & 277 & 18.2 \\
11.5 & 3.93 & 0.58 & 145 & 317 & 18.8 \\
12.0 & 3.92 & 0.56 & 145 & 271 & 19.1 \\
13.0 & 3.99 & 0.59 & 146 & 107 & 18.8 \\
13.5 & 3.79 & 0.56 & 145 & 143 & 19.2 \\
14.0 & 3.85 & 0.57 & 151 & 158 & 19.6 \\
\hline
\end{tabular}




\section{Results and Discussion}

\subsection{VERTICAL PROFILES OF WIND SPEED AND TANGENTIAL MOMENTUM TRANSFER}

Vertical proliles of non-dimensionalized mean horizontal wind speed and mean tangential momentum transfer $\left(\overline{w^{\prime} u^{\prime}}\right)$ are presented in Figures $2 \mathrm{a}$ and $2 \mathrm{~b}$, respectively. The shape of the wind-speed profile is to be expected: strong shear in the upper half

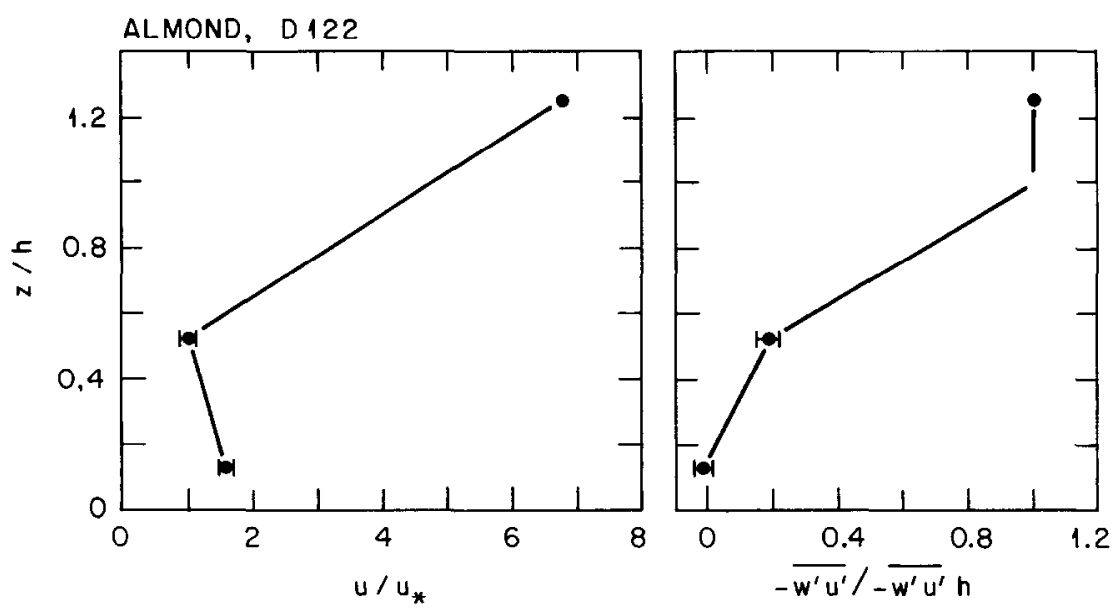

Fig. 2. Mean non-dimensional vertical profiles of: (a) wind speed; and (b) tangential momentum stress. Wind speeds were normalized by friction velocities $\left(u_{*}\right)$ measured above the canopy. Momentum stress values were normalized by their respective quantity measured at $1.26 h$. Error bars represent standard errors.

of the canopy and a secondary maximum below crown closure. The secondary wind maximum is attributed to a net convergence of the vertical flux of momentum transfer, $\left.\partial\left[\overline{\left(w^{\prime} w^{\prime} u^{\prime}\right.}\right) / \partial z\right]$, which exceeds the pressure destruction term in the $\overline{w^{\prime} u^{\prime}}$ budget (Shaw, 1976; Wilson and Shaw, 1977; Meyers and Paw U, 1986). 'Blow-through' effects probably did not contribute to the secondary maximum since they were minimized by the long fetch. The shape of the wind speed profile resembles those measured in forests and orchards (larch, Allen, 1968; spruce, Landsberg and James, 1971; orange, Kalma and Stanhill, 1972) and agricultural crops (wheat, Finnigan, 1979a; soybeans, Baldocchi et al., 1983).

Normalized tangential momentum transfer decreases in magnitude with depth into the canopy, due to momentum absorption by canopy elements (Figure 2b). The absorption of momentum is strongest in the upper half of thc canopy canopy, where about $80 \%$ of the momentum transferred from the atmosphere is absorbed. The level of mean momentum absorption, an estimate of the zero-plane displacement (Thom, 1975 ), is extrapolated to be about $0.70 h$. This value agrees with measurements in other tree canopies (Molion and Moore, 1983; Dolman, 1985). 
Small, positive values of $\overline{w^{\prime} u^{\prime}}$ are observed periodically near the canopy floor. Table II shows that many of these values are significantly different from zero. Measurements of spatial separation in subcanopy wind flow, made on different days during this

TABLE II

Statistics associated with the measurement of $\overline{w^{\prime} u^{\prime}}$ at $0.14 h$ on D122. The standard errors of $\overline{w^{\prime} u^{\prime}}$ were computed as the ratio of the standard deviation of the $\overline{w^{\prime} u^{\prime}}$ measurement divided by the square root of the number of samples, $n(n=8654) .95 \%$ C.I. is the $95 \%$ confidence level.

\begin{tabular}{lcll}
\hline $\begin{array}{l}\text { Time } \\
(\mathrm{hr})\end{array}$ & $\begin{array}{l}\overline{w^{\prime} u^{\prime}} \\
\left(\mathrm{m}^{2} \mathrm{~s}^{-2}\right)\end{array}$ & Std. error & $95 \%$ C.I. \\
\hline 9.0 & $0.0156^{\mathrm{a}}$ & 0.0031 & 0.0061 \\
9.5 & $0.0199^{\mathrm{a}}$ & 0.0038 & 0.0075 \\
10.0 & $0.0235^{\mathrm{a}}$ & 0.0034 & 0.0067 \\
10.5 & 0.0053 & 0.0031 & 0.0060 \\
11.0 & 0.0008 & 0.0031 & 0.0060 \\
11.5 & -0.0022 & 0.0028 & 0.0056 \\
12.0 & -0.0046 & 0.0029 & 0.0057 \\
13.0 & -0.0027 & 0.0024 & 0.0047 \\
13.5 & 0.0036 & 0.0030 & 0.0059 \\
14.0 & $0.0062^{\mathrm{a}}$ & 0.0025 & 0.0049 \\
& & & \\
Avg. & 0.0066 & & \\
Std. dev. & 0.0009 & & \\
$95 \%$ C.I. & 0.0067 & & \\
\hline
\end{tabular}

a Indicates that the mean value is significantly different from zero at the $95 \%$ confidence interval.

experiment, also proved that positive values of $\overline{w^{\prime} u^{\prime}}$ occurred at different locations in the subcanopy. Positive $\overline{w^{\prime} u^{\prime}}$ values were measured when two anemometers at $0.14 h$ were separated laterally by 9 and $3 \mathrm{~m}$ (Table III). Raupach et al. (1986) observed positive $\overline{w^{\prime} u^{\prime}}$ values in their wind tunnel study. They state that these positive values, if real, may be associated with systematic recirculations in element wakes and may represent the existence of significant dispersive fluxes. Given that the sonic anemometers were positioned on the leeward side of an almond tree, they may have been responding to wakes and vortices shed by the tree, as hypothesized by Raupach et al. (1986).

On the other hand, one may argue that the positive $\overline{w^{\prime} u^{\prime}}$ values are an artifact of measurement error since we are measuring small covariance values. The primary error that could have affected our data is a tilt error. However, since we were able to level the anemometer to within one degree of horizontal, the tilt error associated with the measurement of $\overline{w^{\prime} u^{\prime}}$ should be less than $\pm 14 \%$ (Dyer, 1981). Errors associated with measuring fluctuations of wind components should also be small since the resolution of the sonic anemometer is $0.0024 \mathrm{~m} \mathrm{~s}^{-1}$.

Verification of the existence of a dispersive term is important in modelling subcanopy horizontally-averaged flow and exchanges (see Raupach and Shaw, 1982). Presently, 


\section{TABLE III}

Values of tangential momentum transfer measured in the subcanopy trunkspace at $0.14 h$ on days 120 and 121 . dy is the lateral separation distance.

\begin{tabular}{|c|c|c|c|}
\hline \multirow[t]{2}{*}{ Day } & \multirow[t]{2}{*}{$\begin{array}{l}\text { Time } \\
\text { (hr) }\end{array}$} & \multicolumn{2}{|c|}{$\begin{array}{l}\overline{w^{\prime} u^{\prime}} \\
\left(\mathrm{m}^{2} \mathrm{~s}^{-2}\right)\end{array}$} \\
\hline & & $\begin{array}{l}\text { In row } \\
d y=0\end{array}$ & $\begin{array}{l}\text { In row } \\
\mathrm{dy}=3 \mathrm{~m}\end{array}$ \\
\hline \multirow[t]{9}{*}{120} & 1130 & 0.0053 & 0.0040 \\
\hline & 1200 & 0.0183 & 0.0087 \\
\hline & 1230 & 0.0046 & 0.0042 \\
\hline & 1430 & 0.0029 & 0.0045 \\
\hline & 1500 & 0.0098 & 0.0105 \\
\hline & 1530 & 0.0038 & -0.0011 \\
\hline & 1600 & 0.0077 & 0.0095 \\
\hline & 1630 & 0.0131 & 0.0007 \\
\hline & & $\begin{array}{l}\text { In row } \\
\text { dy }=0\end{array}$ & $\begin{array}{l}\text { Between rows } \\
\mathrm{dy}=9 \mathrm{~m}\end{array}$ \\
\hline \multirow[t]{8}{*}{121} & 1000 & -0.0070 & 0.0047 \\
\hline & 1030 & -0.0004 & 0.0058 \\
\hline & 1100 & 0.0084 & -0.0023 \\
\hline & 1200 & 0.0014 & -0.0047 \\
\hline & 1300 & 0.0057 & -0.0031 \\
\hline & 1400 & 0.0122 & 0.0003 \\
\hline & 1430 & 0.0207 & 0.0007 \\
\hline & 1500 & 0.0098 & -0.0010 \\
\hline
\end{tabular}

the dispersive term inside a plant canopy is assumed to equal zero, based on measurements made above a model canopy (Raupach et al., 1980, 1986). The dispersive term arises from the temporal and spatial averaging of a turbulent flux (Raupach and Shaw, 1982):

$$
\left\langle w^{\prime \prime} u^{\prime \prime}\right\rangle=\left\langle\overline{w^{\prime} u^{\prime}}\right\rangle+\left\langle\overline{w^{\prime \prime} u^{\prime \prime}}\right\rangle,
$$

where the term on the left-hand side is the total tangential momentum flux, the first term on the right-hand side is the spatially averaged tangential momentum flux and the second term on the right-hand side is the dispersive term. The dispersive term represents the covariance arising from the spatial correlation of quantities, time-averaged, but varying in position (Raupach and Shaw, 1982). The brackets denote horizontal averaging, the single primes denote fluctuations from the temporal mean and the double primes denote fluctuations from the spatially averaged quantity. The term $\left\langle\overline{w^{\prime \prime} u^{\prime \prime}}\right\rangle$ should be less than or equal to zero since momentum is generally transferred toward the surface. Thus, the positive $\overline{w^{\prime} u^{\prime}}$ values, observed near the orchard floor (Tables II and III), may imply the existence of a non-zero dispersive term in the subcanopy because non-zero values are needed to balance the positive $\left\langle\overline{w^{\prime} u^{\prime}}\right\rangle$ values, according to 
Equation (3). Since we provide only inferential evidence of the existence of a non-zero dispersive term here, we recommend that future experiments be conducted to measure this term directly.
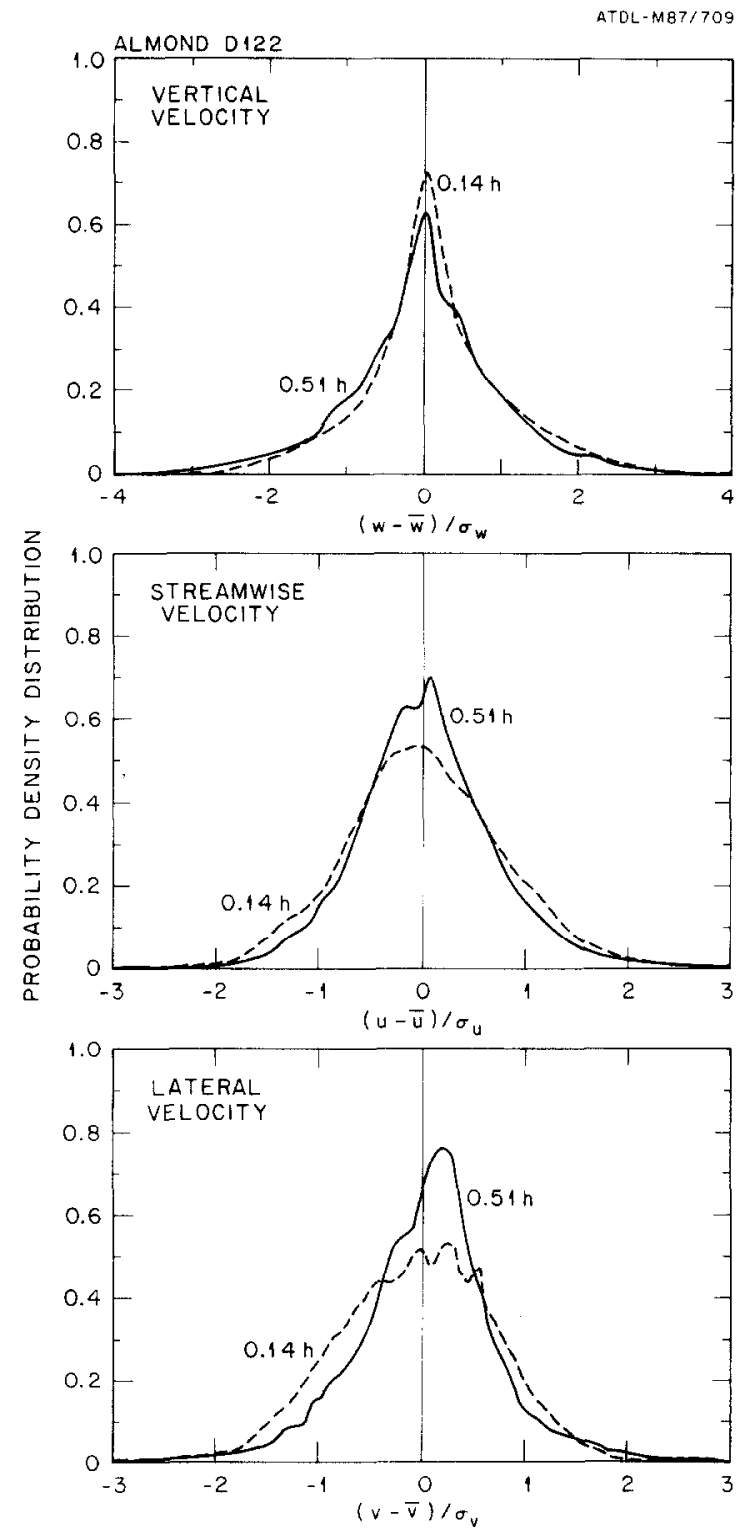

Fig. 3. Probability density distributions of the differences from the mean of: (a) vertical wind velocity; (b) streamwise wind velocity; and (c) lateral wind velocity measured in an almond orchard. These distributions are normalized by their respective standard deviations. These data are from D122 0930 to $1000 \mathrm{hr}$. 


\subsection{Probability density distributions of Wind velocity COMPONENTS}

Information regarding probability density distributions of wind velocity components is needed to understand processes such as the liberation of spores, pollen and particles from leaves and the breakage of limbs (Shaw et al., 1979; Shaw and McCartney, 1985). Figures $3 \mathrm{a}, 3 \mathrm{~b}$, and $3 \mathrm{c}$ show probability density distributions of the differences between the vertical, streamwise and lateral velocity components and their respective means measured at 0.51 canopy height $(h)$ and $0.14 h$. These distributions are normalized by their respective standard deviations $(\sigma)$. The statistics associated with these frequency distributions are presented in Table IV. The frequency distributions of the wind velocity components are non-Gaussian at both levels in the canopy, as indicated by relatively

TABLE IV

Statistics of wind velocity components on D122 in an almond orchard. Vr is variance, Sk is skewness and $\mathrm{Kr}$ is kurtosis.

\begin{tabular}{|c|c|c|c|c|c|c|c|c|c|c|c|}
\hline \multicolumn{12}{|c|}{ Sonic anemometer \# $1,0.51 \mathrm{~h}$} \\
\hline Time & $w$ & $u$ & $\mathrm{Vr}_{w}$ & $\mathrm{Vr}_{u}$ & $\mathrm{Vr}_{v}$ & $\mathbf{S k}_{w}$ & $\mathbf{S k}_{u}$ & $\mathbf{S k}_{v}$ & $\mathrm{Kr}_{w}$ & $\mathrm{Kr}_{u}$ & $\mathrm{Kr}_{v}$ \\
\hline hr & \multicolumn{2}{|c|}{$\mathrm{ms} \mathrm{s}^{-1}$} & \multicolumn{3}{|c|}{$\longrightarrow\left(\mathrm{m} \mathrm{s}^{-1}\right)^{2} \longrightarrow$} & & & & & & \\
\hline 9.0 & 0.08 & 0.64 & 0.23 & 0.39 & 0.79 & -0.33 & 1.89 & -1.15 & 5.68 & 6.25 & 3.42 \\
\hline 9.5 & 0.06 & 0.80 & 0.29 & 0.72 & 1.15 & -0.35 & 1.61 & -1.24 & 5.66 & 3.71 & 2.89 \\
\hline 10.0 & 0.08 & 0.73 & 0.31 & 0.57 & 1.08 & -0.07 & 1.73 & -1.20 & 5.09 & 4.43 & 3.04 \\
\hline 10.5 & 0.12 & 0.65 & 0.27 & 0.40 & 0.76 & -0.11 & 1.53 & -1.26 & 5.62 & 4.33 & 3.55 \\
\hline 11.0 & 0.12 & 0.64 & 0.25 & 0.35 & 0.72 & -0.09 & 1.36 & -1.54 & 4.42 & 4.03 & 4.03 \\
\hline 11.5 & 0.10 & 0.58 & 0.28 & 0.35 & 0.68 & -0.35 & 1.34 & -1.69 & 6.28 & 4.05 & 5.51 \\
\hline 12.0 & 0.09 & 0.62 & 0.25 & 0.34 & 0.77 & -0.25 & 1.41 & -1.47 & 5.19 & 4.03 & 3.80 \\
\hline 13.0 & 0.11 & 0.55 & 0.23 & 0.29 & 0.63 & -0.24 & 1.33 & -1.52 & 5.41 & 4.96 & 5.34 \\
\hline 13.5 & 0.09 & 0.56 & 0.26 & 0.28 & 0.64 & -0.55 & 1.29 & -1.75 & 6.57 & 4.39 & 5.29 \\
\hline 14.0 & 0.10 & 0.57 & 0.27 & 0.34 & 0.49 & -0.75 & 0.91 & -1.33 & 7.33 & 4.65 & 5.84 \\
\hline Avg. & 0.10 & 0.63 & 0.26 & 0.40 & 0.77 & -0.31 & 1.44 & -1.42 & 5.72 & 4.48 & 4.27 \\
\hline SE & 0.01 & 0.02 & 0.01 & 0.04 & 0.06 & 0.06 & 0.08 & 0.06 & 0.25 & 0.21 & 0.33 \\
\hline \multicolumn{12}{|c|}{ Sonic anemometer \# $2,0.14 h$} \\
\hline 9.0 & 0.06 & 0.83 & 0.06 & 0.49 & 1.28 & -0.02 & 1.46 & -1.25 & 7.55 & 3.99 & 2.80 \\
\hline 9.5 & 0.07 & 1.03 & 0.07 & 0.91 & 1.85 & 0.12 & 1.52 & -1.22 & 6.58 & 3.75 & 2.36 \\
\hline 10.0 & 0.08 & 0.93 & 0.07 & 0.65 & 1.70 & 0.09 & 1.49 & -1.29 & 5.93 & 3.81 & 2.79 \\
\hline 10.5 & 0.10 & 0.89 & 0.06 & 0.45 & 1.31 & 0.19 & 1.37 & -1.00 & 5.42 & 4.31 & 2.57 \\
\hline 11.0 & 0.09 & 1.02 & 0.07 & 0.49 & 1.10 & -0.37 & 1.08 & -0.95 & 7.15 & 4.64 & 3.04 \\
\hline 11.5 & 0.09 & 0.86 & 0.06 & 0.40 & 1.07 & 0.13 & 1.01 & -1.21 & 6.93 & 3.94 & 3.16 \\
\hline 12.0 & 0.09 & 0.88 & 0.06 & 0.39 & 1.23 & -0.56 & 1.22 & -1.25 & 6.81 & 3.73 & 3.17 \\
\hline 13.0 & 0.09 & 0.80 & 0.05 & 0.36 & 0.74 & -0.11 & 0.75 & -1.10 & 7.87 & 4.15 & 3.45 \\
\hline 13.5 & 0.09 & 0.86 & 0.06 & 0.42 & 0.98 & -0.11 & 0.75 & -1.13 & 6.75 & 4.48 & 3.10 \\
\hline 14.0 & 0.07 & 0.95 & 0.05 & 0.41 & 0.44 & -0.12 & 0.59 & -1.11 & 7.61 & 4.64 & 4.62 \\
\hline Avg. & 0.08 & 0.90 & 0.06 & 0.50 & 1.17 & -0.08 & 1.12 & -1.15 & 6.86 & 4.14 & 3.11 \\
\hline SE & 0.00 & 0.02 & 0.00 & 0.05 & 0.13 & 0.07 & 0.10 & 0.03 & 0.23 & 0.11 & 0.19 \\
\hline
\end{tabular}


high kurtosis and non-zero skewness values. The features associated with these frequency distributions are similar to those reported by Shaw et al. (1979) and Shaw and McCartney (1985) for wind flow in agricultural crops.

Vertical wind velocity at $0.14 h$ is more intermittant than at $0.51 h$, as indicated by the higher peak and greater kurtosis at the lower level (Table IV). This result is expected because the foliage attenuates or deflects some vertical wind gusts and thus prevents them from penetrating deep into the subcanopy trunkspace. Further evidence that the foliage in the upper canopy restricts the penetration of vertical wind deep into the canopy is given by the correlation between vertical velocities observed at the two levels. The correlation coefficient between $w$ at 0.51 and $0.14 h$ is only $0.30 \pm 0.01$.

The influence of large vertical wind gusts can be examined via the frequency of occurrence above a chosen threshold. Vertical wind gusts exceeding two times the normalized standard deviation of the mean $\left.(\mid w-\bar{w}) / \sigma_{w} \mid>2\right)$ occurred about $7.2 \%$ of the time at midcanopy and about $4.9 \%$ of the time in the subcanopy.

The mean vertical velocities are non-zero, though small in magnitude, and are directed upward at both levels in the canopy (Table IV). Tilt errors cannot account for these values since the tilt of the instrument array was less than one degree. On the other hand, measurement error may contribute to these non-zero values. We cannot conclude with confidence that the vertical velocities were significantly different from zero since the zero offset of the anemometers generally ranged between \pm 0 to $0.10 \mathrm{~m} \mathrm{~s}^{-1}$. If real, these non-zero vertical velocities probably result from the recirculating eddies established in the lee of the upwind trees or elements, as suggested by Raupach et al. (1980); thus one should not mathematically rotate the coordinate axes for wind velocity components inside a canopy to force $\bar{w}$ to zero.

Streamwise and lateral velocity distributions (Figures $3 b$ and $3 c$; Table IV) are more peaked and exhibit less variance in the midcanopy than in the subcanopy. Streamwise and lateral velocity distributions are probably more peaked at midcanopy than in the subcanopy since they are reflecting the influence of a higher proportion of wake and shear-generated eddies, as opposed to large intermittant eddies from above. On the other hand, variances are probably greater in the subcanopy trunkspace since the mean wind flow regime in the subcanopy is influenced by penetrating intermittant gusts that are much greater than the mean. This contention is supported by the horizontal velocity power spectra presented in Baldocchi and Hutchison (1987).

The intermittency of horizontal wind gusts can be quantified by examining the frequency of occurrence above a chosen threshold level. Wind gusts exceeding two times the normalized standard deviation of the mean $\left(\left|(u-\bar{u}) / \sigma_{u}\right|>2 ; \mid\left(v-\bar{v} / \sigma_{v} \mid>2\right)\right.$ occur about 2 to $3 \%$ of the time for the streamwise and the lateral wind velocity components. This intermittent occurrence of relatively large wind gusts supports Shaw and McCartney's (1985) contention that time-averaged wind speed determinations may be inadequate for the interpretation of spore release and particle impaction, processes which are non-linearly related to wind speed.

The streamwise velocity frequency distributions (Figure 3b) also indicate the occurrence of negative velocities. This observation, coupled with the large variance in 
lateral velocity, further supports the postulated existence of a secondary circulation in the lee of the upwind tree. Frequency distributions of the streamwise wind component are not available in the literature for comparison with our data. However, Maitani (1978) observed negative values of streamwise velocity immediately above a plant canopy. $\mathrm{He}$ states that this occurrence is associated with regions having great turbulence.

\subsection{Vertical PROFILes of TURBUlent STATISTICS}

Figures $4 \mathrm{a}, 4 \mathrm{~b}$, and $4 \mathrm{c}$ present vertical profiles of turbulent intensities (i), skewness (Sk) and kurtosis $(\mathrm{Kr})$. Turbulent intensities decreased with depth from midcanopy. The relationship among turbulent intensity components is $i_{v}>i_{u}>i_{w}$. The magnitude of $i$ for the $v, u$, and $w$ components ranges between about 1.2 and 1.4, 0.8 and 1.0, and 0.2
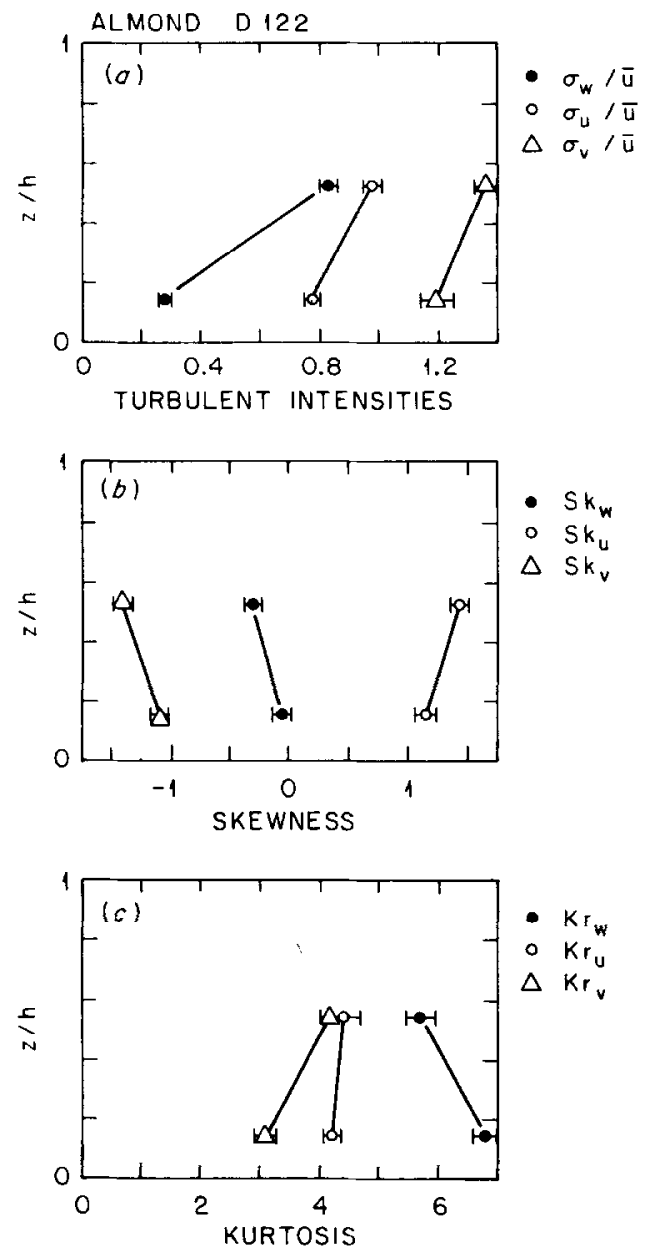

Fig. 4. Mean non-dimensional vertical profiles of: (a) turbulent intensities; (b) skewness; and (c) kurtosis. These data are from the ten periods shown in Table IV. Error bars represent standard errors. 
and 0.8 , respectively. Turbulent intensities for the vertical component are smaller than those for the horizontal components because the presence of the ground surface acts to restrict the scale of vertical fluctuations (Finnigan, 1979a).

Cionco (1972) reports that horizontal turbulent intensities are constant with height in simple canopies. In a forest canopy, he reports that a maximum occurs in the crown and a minimum occurs in the trunk space. More recent data by Shaw et al. (1974) and Wilson et al. (1982) show turbulent intensities increasing with depth into a corn canopy, while Finnigan (1979a) shows that they decrease with depth in a wheat canopy. The relationship between turbulent intensities and height is a function of the leaf area distribution and the flexibility of the canopy elements (Finnigan, 1979a), thus accounting for the different relationships reported in the literature.

The magnitude of turbulent intensities for the horizontal wind components in the almond orchard are in broad agreement with values measured in forest canopies (Cionco, 1972). Slightly smaller values have been reported for most agricultural crops. These values typically range between 0.2 and 0.8 for the horizontal velocity components and between 0.1 and 0.5 for the vertical velocity component (e.g., Shaw et al., 1974; Finnigan, 1979a). Wilson et al. (1982), on the other hand, report values exceeding 4.0 in the lower canopy of a corn crop.

Skewness (Sk) profiles differ significantly for the three wind velocity components (Figure $4 b$ ). $S_{k}$ values are negative at midcanopy and approach zero in the subcanopy trunkspace. $\mathrm{Sk}_{u}$ values are greater than 1 , and $\mathrm{Sk}_{v}$ values are less than -1 and increase with depth.

The magnitude and signs of the $w$ and $u$ skewness values resemble those measured in an artificial canopy by Seginer et al. (1976) and Raupach et al. (1986) and in a larch plantation (Allen, 1968). They also broadly agree with midcanopy skewness values theoretically derived for a corn crop by Shaw (1985). The positive nature of $\mathrm{Sk}_{u}$ and negative nature of $\mathrm{Sk}_{w}$ suggest that these components are dominated by large intermittent gusts (Finnigan, 1979b; Raupach et al., 1986). $\mathrm{Sk}_{w}$ values approach zero near the canopy floor because the ground deflects downward moving gusts into horizontal motions (Raupach et al., 1986). The non-zero skewness of the $v$ component differs from what is reported by Seginer et al. (1976). Our observation may result from the hypothesized systematic wake circulation due to canopy elements.

Kurtosis (Figure 4c) values exceed 3, the value associated with a Gaussian distribution, at all levels and for all velocity components. This further supports the contention that canopy flow is driven by intermittent large eddies. Values for $\mathbf{K r}_{w}$ are largest, ranging between 5 and 7 , while kurtoses for the two horizontal velocity components range between 3 and 5 . $\mathrm{Kr}_{w}$ increases with depth below midcanopy, while $\mathrm{Kr}_{u}$ is constant with height and $\mathrm{Kr}_{v}$ decreases with depth below midcanopy. The magnitudes and shapes of the vertical profiles of $\mathrm{Kr}_{w}$ and $\mathrm{Kr}_{u}$ are in excellent agreement with data of Raupach et al. (1986) from an artificial canopy. No data on $\mathrm{Kr}_{v}$ are available for comparison.

Models of third-order moments (e.g., Shaw, 1985; Meyers and Paw U, 1986) utilize the quasi-Gaussian approximation to close their set of equations; for example, this 
approximation assumes that $\overline{w^{\prime}} 4=3\left(\sigma_{w}^{2}\right)^{2}$. The data in Figure $4 \mathrm{c}$ show that the quasiGaussian approximation does not hold for $w$ and $u$ since $\mathrm{Kr}$ is 30 to $120 \%$ greater than 3. Consequently, other parameterizations may be needed to close the set of equations used to model the third-order moments, if they are sensitive to errors in the parameterization of the fourth-order moments.

Profiles of the mixed third-order terms used in higher order closure models are presented in Figure 5. These values are normalized by their respective standard

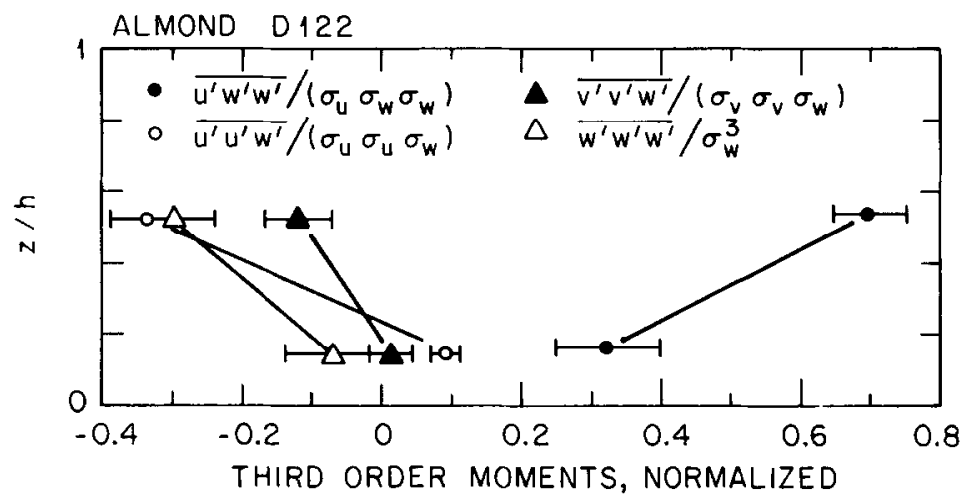

Fig. 5. Mean non-dimensional vertical profiles of mixed third-order turbulent terms. These values are normalized by their respective standard deviations and are comprised of the ten periuds shown in Table IV. Error bars represent standard errors.

deviations. The $\overline{u^{\prime} w^{\prime} w^{\prime}}$ terms are positive and $\overline{u^{\prime} u^{\prime} w^{\prime}}, \overline{v^{\prime} v^{\prime} w^{\prime}}$ and $\overline{w^{\prime} w^{\prime} w^{\prime}}$ term are negative (with the exception of $\overline{u^{\prime} u^{\prime} w^{\prime}}$ and $\overline{v^{\prime} v^{\prime} w^{\prime}}$ in the subcanopy), which is in agreement with the theoretical calculations of Shaw (1985). All values of the mixed third-order terms decrease in magnitude with depth below midcanopy and are smaller than the values associated with $\mathrm{Sk}_{u}$, as shown in Shaw (1985) and Raupach et al. (1986).

Values of $\overline{u^{\prime} w^{\prime} w^{\prime}}$ do not approach zero in the subcanopy trunkspace, as has been reported experimentally and theoretically by Shaw (1985) in corn. Differences in the vertical distribution of foliage between the corn and almond orchard canopy probably account for this difference in the profile of $\overline{u^{\prime} w^{\prime} w^{\prime}}$.

Positive values of $\overline{u^{\prime} u^{\prime} w^{\prime}}$ and $\overline{v^{\prime} v^{\prime} w^{\prime}}$, observed in the subcanopy, represent an upward transport of kinetic energy. Typically, kinetic energy is transported downward above and within a horizontally homogeneous canopy (Maitani, 1978; Shaw, 1985). Our observation is probably an artifact of the systematic circulation, which exists in the lee of the upwind tree.

\subsection{SPATIAL CORRELATIONS}

Spatial correlations are important in understanding the coupling of wind flow within canopies. Unfortunately, little data are available to compare with our measurements. 
The correlation coefficient $(r)$ between $u$ at $0.51 h$ and $0.14 h$ is $0.42 \pm 0.02$, while that of $v$ at these two levels is $v$ is $0.72 \pm 0.01$. Thus, the horizontal wind in the subcanopy trunkspace is poorly to moderately coupled with wind in the midcanopy, since eddies large enough to penetrate to the subcanopy and affect wind at both levels simultaneously occur infrequently. Baldocchi and Hutchison (1987) investigate the coupling between wind at two points in more detail by examining the spectral coherence.

The correlation coefficient for the $w$ component at the two levels in the almond canopy is $0.30 \pm 0.01$, as stated above. Crowther and Hutchings (1985) examined the correlation between vertical wind speeds at $0.54 h$ and $0.79 h$ in a spruce canopy. With a zero time lag, they reported that the cross-correlation coefficient is about 0.85 . The differences between the correlation coefficient reported here and that reported by Crowther and Hutchings (1985) probably results from differences in sensor location and canopy structure.

\subsection{CONDITIONAL SAMPLING OF TANGENTIAL MOMENTUM STRESS}

Conditional sampling has been used to describe the detailed structure of tangential momentum stress in plant canopies. This technique has been described by Finnigan (1979b), Raupach (1981), Raupach et al. (1986), and Shaw et al. (1983). Conditional sampling involves determining the contribution of the instantaneous product of $w^{\prime}$ and $u^{\prime}$ to the computation of the mean covariance $\overline{w^{\prime} u^{\prime}}$, based on a plane with $w^{\prime}$ as the $y$-axis and $u^{\prime}$ as the $x$-axis. The four quadrants can be defined as follows:

quadrant 1: $u^{\prime}>0, w^{\prime}>0$, outward interactions,

quadrant 2: $u^{\prime}<0, w^{\prime}>0$, burst or ejection,

quadrant 3: $u^{\prime}<0, w^{\prime}<0$, inward interactions ,

quadrant 4: $u^{\prime}>0, w^{\prime}<0$, sweep or gust .

Information regarding the importance of turbulent events of different magnitudes is obtained by defining a hole size $(H)$ :

$$
H=\left|w^{\prime} u^{\prime}\right| /\left|\overline{w^{\prime} u^{\prime}}\right| .
$$

Conditional sampling at different hole sizes is performed using the criteria that $I_{i, H}$ equals 1 if $u^{\prime}$ and $w^{\prime}$ lie on the $i$ th quadrant and $\left|w^{\prime} u^{\prime}\right|>=H\left|\overline{w^{\prime} u^{\prime}}\right|$. Otherwise $I_{i, H}$ equals 0 . Subsequently, the conditionally averaged Reynold's stress is defined as:

$$
\left(w^{\prime} u^{\prime}\right)_{i, H}=(1 / \tau) \int_{0}^{\tau} w^{\prime} u^{\prime}(t) I_{i, H} \mathrm{~d} t,
$$

where $\tau$ is the length of the averaging period and $t$ is time. A stress fraction can be computed as:

$$
S(i, H)=\left(w^{\prime} u^{\prime}\right)_{i, H} / \overline{w^{\prime} u^{\prime}}
$$


and the time fraction associated with these turbulent events is:

$$
T(i, H)=(1 / \tau) \int_{0}^{\tau} I_{i, H}(t) \mathrm{d} t
$$

About $50 \%$ of the total stress fraction at $0.51 \mathrm{~h}$ results from events equal to or larger than $H=25$ (Figure 6a); these events occur less than $2 \%$ of the time (Figure $6 \mathrm{~b}$ ). At

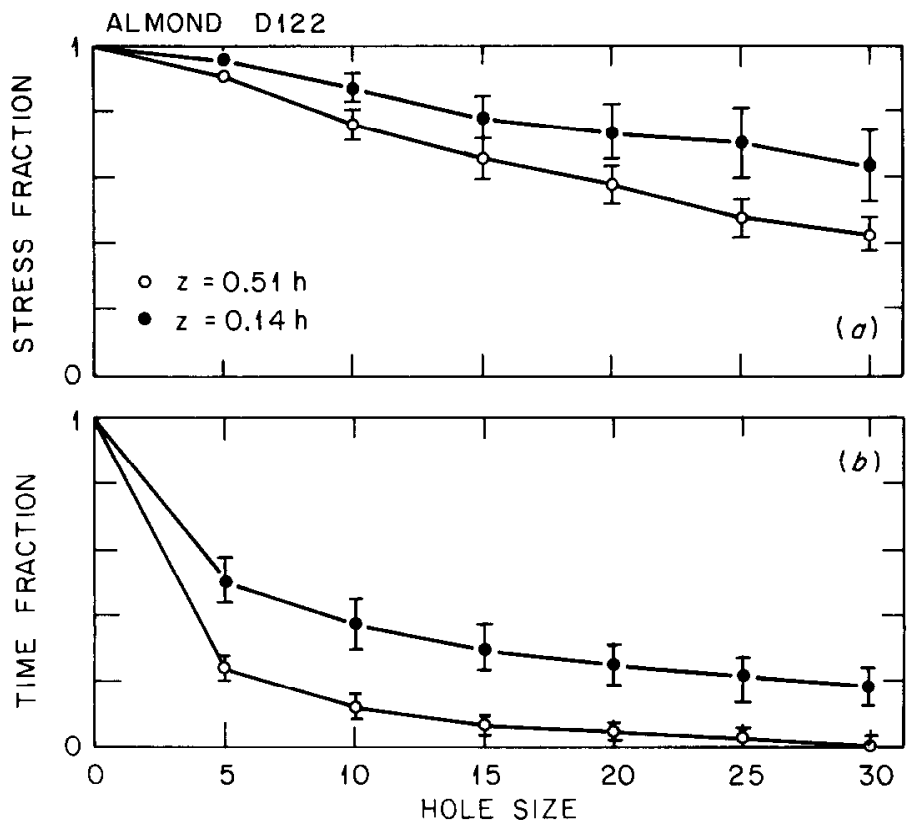

Fig. 6. (a) The sum of the stress fractions for the four quadrants at varying hole sizes. (b) The sum of the time fractions for the four quadrants at varying hole sizes. These data are from the periods shown in Table IV. Error bars represent standard errors.

$0.14 h$, about $64 \%$ of the total stress fraction results from events equal to or larger than $H=30$. These events occur less than $20 \%$ of the time. These results, thus, support the contention that momentum transfer in a plant canopy is dominated by large intermittant events.

Shaw et al. (1983) came to a similar conclusion for momentum transfer in a corn crop. However, they showed that $50 \%$ of the total stress fraction at $0.79 \mathrm{~h}$ came from events only five times greater than $H$ and that these events occurred only about $6 \%$ of the time. Finnigan (1979b), on the other hand, reported that significant turbulent events occurred at hole sizes exceeding 30 in wheat.

Figure 7 shows the stress fractions $(S(i, H))$ as functions of hole size for each of the quadrants in the $u-w$ plane. At midcanopy $(0.51 h)$, tangential momentum stress is comprised of the relatively small sum of large offsetting contributions by inward and 


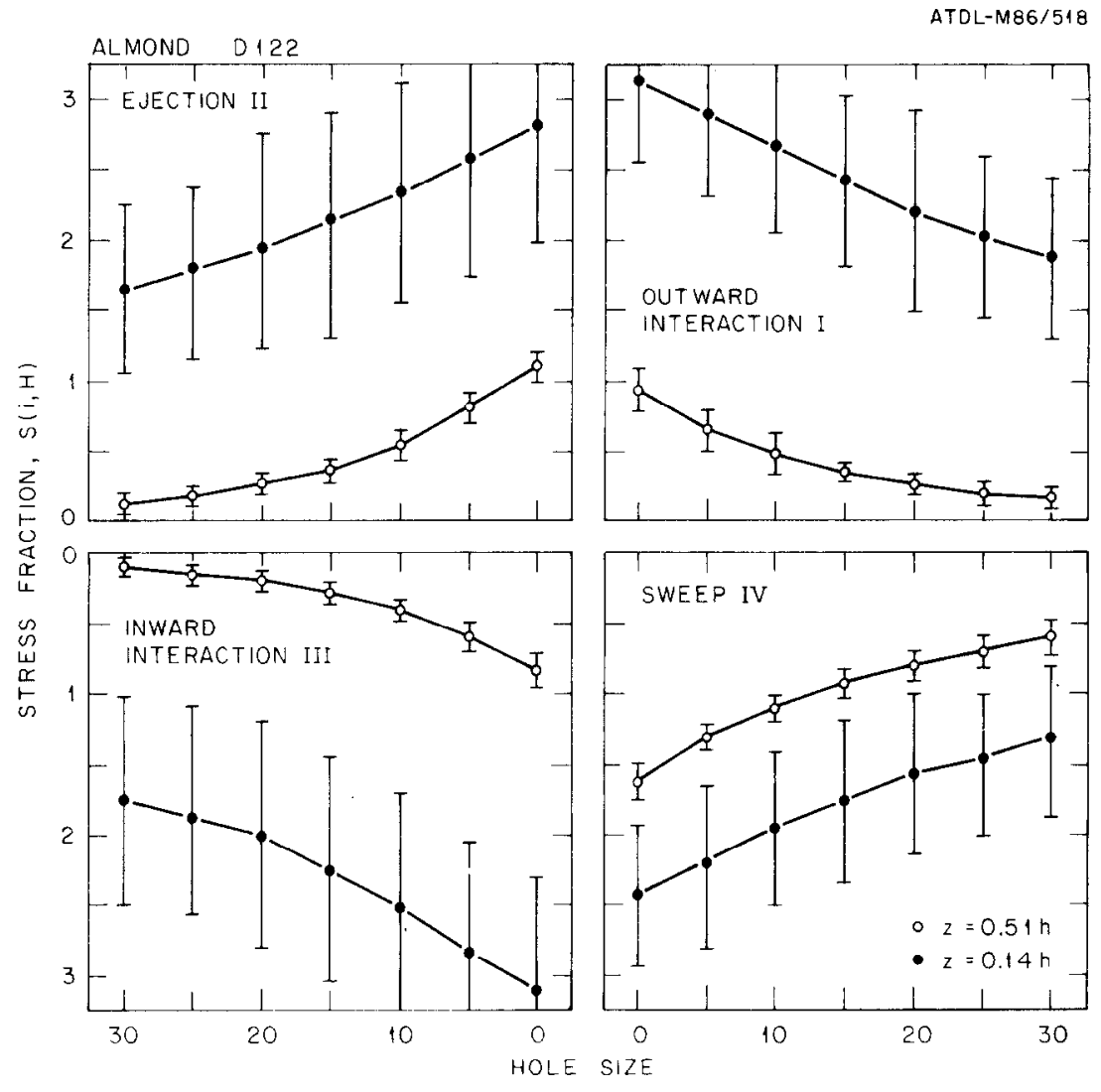

Fig. 7. Stress fractions, $S(i, H)$ at two levels in an almond orchard. These data are from the periods shown in Table IV. Error bars represent standard errors.

outward interactions, ejections and sweeps. Sweeps, however, predominate, providing the main mechanism of momentum transfer. For example, at a hole size of 0 , the ratio of sweeps to outward interactions $(S(4,0) / S(1,0))$, ejections $(S(4,0) / S(2,0))$, and inward interactions $(S(4,0) / S(3,0))$ are $1.78,1.37$, and 1.92, respectively. Furthermore, the contribution to tangential momentum stress by sweeps increases with hole size; the sweep fraction is still substantial at hole sizes as large as 30 , whereas the contribution by the other components diminishes to near zero at that hole size.

Finnigan (1979b) also found that momentum stress at midcanopy in a wheat field was the small sum of large offsetting contributions by the four stress fractions and that these stress fractions extended out to rather large hole sizes. On the other hand, Finnigan (1979b) reported that contributions to momentum stress by inward interactions and ejections were negligible at hole sizes exceeding 5 and that sweeps were several times greater than the magnitude of ejections. Shaw et al. (1983), Raupach (1981) and Raupach et al. (1986) reported that the magnitude of the stress fractions in a corn field and artificial canopy were much less than 1 and that the interaction terms contributed 
little to momentum transfer. These workers also showed a dropoff of the influence of the interactions and ejections terms at hole sizes on the order of 10 to 15 . However, the ratio between sweeps and ejections reported by Raupach et al. (1986) $(S(4,0) / S(2,0)=1.3)$ is similar to our value. They stated that larger ratio values reported by Finnigan (1979b) and Raupach (1981) were a result of anemometry errors.

Near the canopy floor $(z=0.14 h)$, another picture describing the structure of tangential momentum stress evolves. As reported above (Figure 2b), momentum stress near the floor of the almond orchard is generally positive. Figure 7 provides an explanation for this observation by showing that inward and outward interaction and ejection stress fractions are greater than the sweep stress fraction; the stress fraction ratios, $S(4,0) / S(1,0), S(4,0) / S(2,0)$, and $S(4,0) / S(3,0)$ are $0.77,0.86$, and 0.79 , respectively. The structure of momentum stress at $0.14 \mathrm{~h}$ resembles that at midcanopy; e.g., momentum stress is composed of the relatively small sum of large offsetting contributions by inward and outward interactions, ejections and sweeps. The large contributions from the interaction terms suggest either sloshing of the air near the floor of the orchard canopy, a phenomena often observed with smoke releases in forest canopies (Oliver, 1973), or the existence of a systematic wake circulation in the lee of the upwind tree. We cannot compare our results with those of Raupach et al. (1986), who also reported positive $\overline{w^{\prime} u^{\prime}}$ values near the bottom of a canopy, since they did not examine the stress fractions at this level.

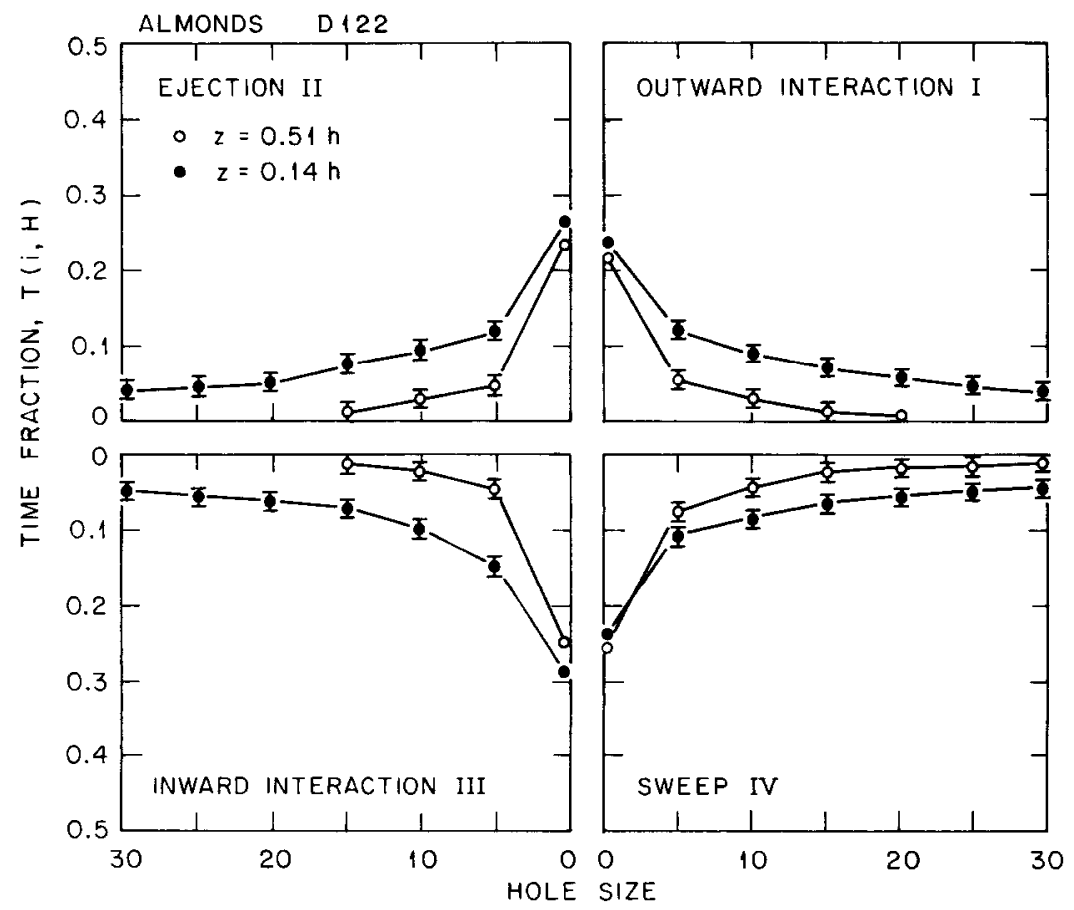

Fig. 8. Time fractions, $T(i, H)$ at two levels in an almond orchard. These data are from the periods shown in Table IV. Error bars represent standard errors. 
Although it has been shown that a disproportionate amount of momentum stress in the midcanopy is due to sweeps, the time fractions $(T(i, H))$ associated with the four stress fractions are relatively uniform (Figure 8) in comparison. At $0.51 h$, the time fraction ratios between sweeps and outward interactions $(T(4,0) / T(1,0))$, ejections $(T(4,0) / T(2,0))$, and inward interactions $(T(4,0) / T(3,0))$ are $1.27,0.98$, and 1.04 , respectively. The smallest time fraction is associated with outward interactions. A high degree of uniformity in the time fractions of momentum stress is also observed in the subcanopy trunkspace. However, a slightly greater time fraction is associated with inward interactions.

\section{Summary}

A preliminary experiment was conducted to examine the spatial variability of turbulence in a uniform canopy. Here, data on the vertical structure of three-dimensional turbulence measured above and within an almond orchard are examined in detail. Strong wind shear is observed in the upper half of the canopy. Conditional sampling of the turbulence measurements show that infrequent sweeps provide the predominant mechanism for tangential momentum stress in the canopy crown. These results, thus, support the contention that momentum exchange in a plant canopy is driven by large intermittent eddies. In the subcanopy trunkspace, a secondary wind speed maximum and positive tangential momentum stress is observed. At this level, outward and inward interactions provide the main mechanism for tagential momentum stress. These observations suggest the possibility of a non-zero dispersion term, as described by Raupach and Shaw (1982), or a secondary circulation in the lee of the tree trunks.

The degree of turbulence inside the almond orchard is quite large. Turbulent intensities for the horizontal wind components range between 0.8 and 1.4 , while those for vertical velocities range between 0.2 and 0.8 . The frequency distribution of wind velocity components is non-Gaussian. Skewness values for the two horizontal wind velocity components exceed 1 in magnitude, skewness for vertical velocity is closer to 0 and kurtosis values for the three wind velocity components exceed 3 . These observations suggest that the quasi-Gaussian approximation used to close higher-order closure models needs to be re-examined.

Due to limitations in the number of available instruments, periods with winds from undesirable directions and the limited time-frame available to conduct this experiment, we were unable to make turbulence measurements at other levels in the canopy. Future experiments should focus on defining the vertical structure of turbulence in plant canopies in finer detail; we have recently performed such an experiment in a deciduous forest near our laboratory in Oak Ridge, TN. Future experiments should also attempt to measure turbulent structure at multiple locations inside plant canopies in order to investigate the existence of a dispersive term, including the conditions on which it may or may not exist. 


\section{Acknowledgements}

This work was sponsored by the U.S. Department of Energy. D.D.B. was a staff biometeorologist at Oak Ridge Associated Universities, which conducts research for the U.S.D.O.E. under contract DE-AC05-760R0033. We are grateful to Ron Cionco and his staff from the U.S. Army Atmospheric Sciences Laboratory for their assistance during this experiment. Appreciation is also extended to Drs Tilden Meyers, Roger Shaw, and John Finnigan for their comments and reviews.

\section{References}

Allen, L. H., Jr.: 1986, 'Turbulence and Wind Spectra Within a Japanese Larch Plantation', J. Appl. Meteorol. 7, 73-78.

Bache, D. H.: 1986, 'Momentum Transfer to Plant Canopies: Influence of Structure and Variable Drag', Atmos. Envir. 20, 1369-1378.

Baldocchi, D. D., Verma, S. B., and Rosenberg, N. J.: 1983, 'Characteristics of Air Flow Above and Within a Soybean Canopy', Boundary-Layer Meteorol. 25, 43-54.

Baldocchi, D. D. and Hutchison, B. A.: 1987, 'Turbulence in an Almond Orchard: Spatial Variation in Spectra and Coherence', Boundary-Layer Meteorol. (in press).

Brown, K. W. and Covey, W.: 1966, 'The Energy Budget Evaluation of the Micrometeorological Transfer Processes Within a Corn Field', Agric. Meteorol. 3, 73-96.

Cionco, R. M.: 1972, 'Intensity of Turbulence Within Canopies with Simple and Complex Roughness Elements', Boundary-Layer Meteorol. 2, 453-465.

Corrsin, S.: 1974, 'Limitations of Gradient Transport Models in Random Walks and in Turbulence', $A d v$. Geophys. 18A, 25-60.

Crowther, J. M. and Hutchings, N. J.: 1985, 'Correlated Vertical Wind Speeds in a Spruce Canopy', in B. A. Hutchison and B. B. Hicks (eds.), Forest-Atmosphere Interactions, D. Reidel Publ. Co., Dordrecht, Holland, pp. 543-561.

Denmead, O. T. and Bradley, E. F.: 1985, 'Flux-Gradient Relationships in a Forest Canopy, in B. A. Hutchison and B. B. Hicks (eds.), Forest-Atmosphere Interactions, D. Reidel Publ. Co., Dordrecht, Holland, pp. 421-442.

Dolman, A. J.: 1986, 'Estimates of Roughness Length and Zero Plane Displacement for a Foliated and Non-Foliated Oak Canopy', Agric. Forest Meteorol. 36, 241-248.

Dyer, A.J.: 1981, 'Flow Distortion by Supporting Structures', Boundary-Layer Meteorol. 20, 243-251.

Finnigan, J. J.: 1979a, 'Turbulence in Waving Wheat. I.: Mean Statistics and Honami', Boundary-Layer Meteorol. 16, 181-212.

Finnigan, J. J.: 1979b, 'Turbulence in Waving Wheat. II: Structure of Momentum Transfer, Boundary-Layer Meteorol. 16, 213-236.

Finnigan, J. J.: 1985, 'Turbulent Transport in Flexible Plant Canopies', in B. A. Hutchison and B. B. Hicks (eds.), Forest-Atmosphere Interactions, D. Reidel Publ. Co., Dordrecht, Holland, pp. 443-480.

Finnigan, J. J. and Raupach, M. R.: 1987, 'Modern Theory of Transfer in Plant Canopies in Relation to Stomatal Characteristic', in E. Zeiger, G. Farquhar, and I. Cowan (eds.), Stomatal Function, Stanford University Press. Stanford, CA (in press).

Kalma, J. D. and Stanhill, G.: 1972, 'The Climate of an Orange Orchard: Physical Characteristics and Microclimate Relationships', Agric. Meteorol. 10, 185-201.

Landsberg, J. J. and James, G. B.: 1971, 'Wind Profiles in Plant Canopies, Studies of an Analytical Model', J. Appl. Ecol. 8, 729-741.

Maitani, T.: 1978, 'On the Downward Transport of Turbulent Kinetic Energy in the Surface Layer Over Plant Canopies', Boundary-Layer Meteorol. 14, 571-584.

Meyers, T. P. and Paw U, K. T.: 1986, 'Testing of a Higher-Order Closure Model for Modelling Airflow Within and Above Plant Canopies', Boundary-Layer Meteorol. 37, 297-311.

Molion, L. C. B. and Moore, C. J.: 1983, 'Estimating the Zero-Plane Displacement for Tall Vegetation Using a Mass Conservation Method', Boundary-Layer Meteorol. 26, 115-125. 
Oliver, H. R.: 1973, 'Smoke Trails in a Pine Forest', Weather 28, 345-347.

Raupach, M. R.: 1981, 'Conditional Statistics of Reynold's Stress in Rough Wall and Smooth Wall Turbulent Boundary Layers', J. Fluid Mech. 108, 363-382.

Raupach, M. R.: 1987, 'A Lagrangian Analysis of Scalar Transfer in Vegetation Canopies', Quart. Royal Meteorol. Soc. 113, 107-120.

Raupach, M. R. and Shaw, R. H.: 1982, 'Averaging Procedures for Flow Within Vegetation Canopies', Boundary-Layer Meteorol. 22, 79-90.

Raupach, M. R. and Thom, A. S.: 1981, 'Turbulence In and Above Plant Canopies', Ann. Rev. Fluid Mech. 13, 97-129.

Raupach, M. R., Coppin, P. A., and Legg, B. J.: 1986, 'Experiments on Scalar Dispersion Within a Model Plant Canopy, Part 1: The Turbulent Structure', Boundary-Layer Meteorol. 35, 21-52.

Raupach, M. R., Thum, A. S., and Edwards, I.: 1980, 'A Wind Tunnel Study of Turbulent Flow Close to Regularly Arrayed Rough Surfaces', Boundary-Layer Meteorol. 18, 373-397.

Seginer, I., Mulhearn, P. J., Bradley, E. F., and Finnigan, J. J.: 1976, 'Turbulent Flow in a Model Plant Canopy', Boundary-Layer Meteorol. 10, 423-453.

Shaw, R. H.: 1976, 'Secondary Wind Maxima Inside Plant Canopies', J. Appl. Meteorol. 16, 514-521.

Shaw, R. H.: 1985, Calculation of the Third Moments of the Velocity Field in a Canopy Layer, Proceedings of the 17th Conference on Agricultural and Forest Meteorology, American Meteorological Society, Boston MA, pp. 77-79.

Shaw, R. H. and McCartney, H. A.: 1985, 'Gust Penetration Into Plant Canopies', Atmos. Environ. 19, $827-830$.

Shaw, R. H,, den Hartog, C., King, K. M., and Thurtell, G. W.: 1974, 'Measurements of Mean Wind Flow and Three-Dimensional Turbulence Intensity with a Mature Corn Canopy', Agric. Meteorol. 13, 419-425.

Shaw, R. H., Tavanger, J., and Ward, D. P.: 1983, 'Structure of the Reynold's Stress in a Canopy Layer, J. Clim. Appl. Meteorol 22, 1922-1931.

Shaw, R. H., Ward, D. P., and Aylor, D. E.: 1979, 'Frequency of Occurrence of Fast Gusts of Wind Inside a Corn Canopy', J. Appl. Meteorol. 18, 161-171.

Thom, A. S.: 1975, 'Momentum, Mass and Heat Exchange of Plant Communities', in J. L. Monteith (ed.), Vegation and the Atmosphere, 1, Academic Press, London, pp. 57-109.

Wilson, J. D., Ward, D. P., Thurtell, G. W., and Kidd, G. E.: 1982, 'Statistics of Atmospheric Turbulence Within and Above a Corn Canopy', Boundary-Layer Meteorol. 24, 495-519.

Wilson, N. R. and Shaw, R. H.: 1977, 'A Higher-Order Closure Model for Canopy Flow', J. Appl. Meteorol. 16, 1197-1205.

Wyngaurd, J. C. and Zhang, S. F.: 1985, 'Transducer-Shadow Effects on Turbulence Spectra Measured by Sonic Anemometers', J. Atmos. Oceanic Tech. 2, 548-558. 